\title{
Analisis Keterlaksanaan Model Pembelajaran Creative Problem Solving (CPS) Berbasis Masalah dan Pengaruhnya Terhadap Keterampilan Proses Sains Siswa pada Materi Asam Basa Kelas XI IPA SMA N 10 Kota Jambi
}

\begin{abstract}
Analysis of the Implementation of Creative Problem Solving (CPS) Learning Model based on the problem and its impact on students` science process skills on the acid-base subject matter at 11th-grade science 10 senior high school Jambi
\end{abstract}

\author{
Siti Nurjanah $^{1 *}$, Fuldiaratman', Abu Bakar ${ }^{1}$ \\ ${ }^{1}$ Program Studi Pendidikan Kimia Fakultas Keguruan dan Ilmu Pendidikan Universitas Jambi
}

\begin{abstract}
A B S T R A K
Penelitian ini bertujuan untuk mengetahui sejauh mana keterlaksanaan model creative problem solving berbasis masalah serta pengaruhnya terhadap keterampilan proses sains siswa pada materi asam basa di kelas XI IPA 2 SMAN 10 Kota Jambi. Pendekatan yang digunakan pada penelitian ini adalah pendekatan campuran (mix method) dengan jenis model sequentile exploratory (model urutan penemuan). Teknik pengambilan sampel dilakukan dengan purposive sampling. Terdapat satu kelas yang digunakan sebagai sampel yaitu kelas XI IPA 2. Instrumen penelitian yang digunakan yaitu lembar observasi keterlaksanaan model oleh guru dan siswa serta keterampilan proses sains siswa dan posttest siswa. Teknik analisis data kualitatif data menggunakan Miles and Huberman dan data kuantitatif menggunakan uji korelasi product moment. Keterlaksanaan model creative problem solving (CPS) oleh guru dan siswa telah terlaksana sesuai prinsip model creative problem solving (CPS) setiap pertemuannya. Persentase keterlaksanaan model oleh guru diperoleh skor persentase 70,00\% (Baik), keterlaksanaan model oleh siswa diperoleh skor persentase $71,28 \%$ (Baik), dan keterlaksanaan keterampilan proses sains siswa diperoleh skor persentase 75,34\% (Baik). Korelasi keterlaksanaan model creative problem solving dengan keterampilan proses sains dengan dikategorikan sedang dengan rata-rata $\mathrm{r}_{\mathrm{xy}} 0,4150$. Berdasarkan hasil penelitian disimpulkan bahwa model pembelajaran creative problem solving (CPS) sudah terlaksana dengan baik dan berpengaruh pada peningkatan keterampilan proses sains siswa pada materi asam basa di kelas XI IPA 2 SMAN 10 Kota Jambi.
\end{abstract}

\section{$A B S T R A C T$}

This study aims to determine the implementation of creative problem-solving models base on the problem and its effects on students' science process skills in the acid-base subject matter at 11th-grade 2nd science of 10 Senior High School Jambi, Indonesia. The method used in this study is a mixed approach with a type of sequential exploratory model. The sampling technique is done by purposive sampling. There is one group that is used as a sample, it's 11thgrade 2 nd science. The research instrument used is the observation sheet of the model implementation by the teacher and students as well as the students' science process skills and student's posttest. The qualitative data analysis technique uses Miles and Huberman and quantitative data uses the product-moment correlation test. The implementation of creative problem solving (CPS) models by teachers and students has been carried out according to the principle of creative problem solving (CPS) models at each meeting. The percentage of the feasibility of the model by the teacher obtained a percentage score of $70.00 \%(\mathrm{Good})$, the feasibility of the model by students obtained a percentage score of $71.28 \%$ (Good), and the implementation of the science process skills of students obtained a percentage score of $75.34 \%$ (Good). Correlation of the implementation of the creative problem-solving model with the science process skills categorized as moderate with an average of rxy0.4150. Based on the results of the study it was concluded that the creative problem solving (CPS) learning model had been implemented well and had an effect on improving students' science process skills on the acid-base material in 11th-grade 2nd science of 10 Senior High School Jambi.

Kata kunci : Model Pembelajaran Creative Problem Solving,Keterampilan Proses Sains, Asam dan Basa Keyword : Learning Model Creative Problem Solving, Science Process Skills, Acids and Bases

\footnotetext{
* coresponding author: s.nurjannah47@yahoo.com

DOI: https://doi.org/10.22437/jisic.v10i1.5309
} 


\section{PENDAHULUAN}

Pendidikan nasional adalah pendidikan yang berdasarkan Pancasila dan UUD yang berakar pada nilai agama, kebudayaan nasional dan tanggap terhadap tuntutan zaman (Depdiknas,2013). Tujuan pendidikan nasional menuntun pendidik untuk mengembangkan kompetensi agar terbentuk sumber daya manusia yang kompeten. Oleh karena itu, pembelajaran harus menyentuh tiga ranah yaitu sikap, pengetahuan, dan keterampilan. Ranah sikap dilaksanakan agar siswa tahu tentang "mengapa". Ranah keterampilan dilaksanakan agar siswa tahu tentang "bagaimana". Ranah pengetahuan dilaksanakan agar siswa tahu tentang "apa". Hasil akhirnya adalah peningkatan dan keseimbangan antara kemampuan untuk menjadi manusia yang baik (soft skills) dan memiliki kecakapan serta pengetahuan untuk hidup secara layak (hard skiils) dari siswa yang meliputi aspek kompetensi sikap, keterampilan, dan pengetahuan (Depdiknas, 2013). Menurut Alawiyah (2013) proses pembelajaran pada kurikulum 2013 ini masih mengalami banyak kendala. Salah satu kendala yang dihadapi adalah guru belum siap dan sulit mengubah pola pikirnya.

Beranjak dari hal tersebut, pembelajaran sains kimia sebagai bagian dari pendidikan, umumnya memiliki peranan penting dalam meningkatkan mutu pendidikan, karena pembelajaran sains kimia termasuk dalam rumpun pembelajaran IPA yang memiliki karakteristik memerlukan kegiatan penyelidikan sebagai bagian dari kerja ilmiah yang melibatkan keterampilan proses sains. Selain itu pembelajaran kimia juga mengembangkan rasa ingin tahu melalui penemuan berdasarkan pengalaman langsung yang dilakukan melalui kerja ilmiah untuk memanfaatkan fakta, membangun konsep, prinsip, teori, dan hukum. Oleh karena itu, peserta didik perlu dibantu untuk mengembangkan sejumlah keterampilan proses supaya mampu menjelajahi dan memahami alam sekitar.
Dengan demikian dalam pembelajaran kimia peserta didik tidak hanya ditekankan untuk menemukan fakta-fakta, konsep-konsep, dan teori-teori dengan keterampilan proses dan sikap ilmiah peserta didik sendiri. Hal ini dimaksud untuk mewujudkan sistem pendidikan sesuai undang-undang No. 20 Tahun 2003 tentang sistem pendidikan Nasional. Berdasarkan undang-undang tersebut dapat disimpulkan tidak hanya ditekankan pada hasil belajar peserta didik tetapi juga pada proses belajar dari peserta didik itu sendiri untuk menumbuhkan kemampuan berpikir, bekerja dan bersikap kritis guna untuk mengembangkan potensi peserta didik.

Ilmu kimia merupakan ilmu yang diperoleh dan dikembangkan berdasarkan eksperimen yang mencari jawaban atas pertanyaan apa, mengapa, dan bagaimana gejala-gejala alam, khususnya yang berkaitan dengan komposisi, struktur dan sifat, transformasi, dinamika dan energitika (Depdiknas,2003). Sehingga untuk mempelajari segala sesuatu yang berkaitan dengan komposisi, struktur dan sifat, transformasi, dinamika dan energitika zat dibutuhkan keterampilan penalaran. Ilmu kimia juga membutuhkan pemikiranpemikiran yang baik untuk menjelaskan maupun mengembangkan materi-materi yang sudah ada serta menemukan yang baru dalam ilmu kimia.

Berdasarkan hasil observasi awal dan wawancara yang dilakukan peneliti kepada guru SMAN 10 Kota Jambi, dalam kegiatan mengajar siswa belum dapat diarahkan untuk memahami suatu permasalahan yang diajukan oleh guru dalam memahami materi kimia kelas XI khususnya pada materi "Asam dan Basa", karena pokok bahasan tersebut mengandung konsep yang perlu dipahami siswa melalui pengamatan langsung dengan menggunakan keterampilan proses. Materi asam basa merupakan salah satu materi yang sulit dipahami dan sebagai pokok pengantar materi selanjutnya yaitu larutan penyangga, hidrolisis, kelarutan dan hasil kali kelarutan. Pembelajaran kimia yang selama ini biasa digunakan oleh guru adalah model PJBL dan diskusi kelompok. Untuk proses kegiatan praktikum tersebut sudah sangat sering 
dilakukan, namun belum dilengkapi dengan prosedur praktikum yang lengkap tanpa ada pengarahan yang baik sesuai dengan kurikulum yang ada serta guru belum sepenuhnya dapat mengarahkan siswa untuk memecahkan masalah dan mengembangkannya. Pembelajaran yang penyampaiannya dilakukan dengan cara menyajikan suatu permasalahan, mengajukan pertanyaan-pertanyaan, memfasilitasi penyelidikan, dan membuka dialog. Permasalahan yang dikaji hendaknya merupakan permasalahan yang kontekstual yang ditemukan oleh siswa dalam kehidupan sehari-hari. Permasalahan harus dipecahkan dengan menerapkan beberapa konsep dan prinsip yang secara stimulan dipelajari dan tercakup dalam kurikulum.

Berdasarkan pengamatan yang dilakukan, masalah ini disebabkan beberapa faktor, diantaranya di dalam pembelajaran guru telah menggunakan model yang dapat melatih keterampilan proses sains siswa di laboratorium tetapi pada prosesnya ada beberapa siswa dapat dilihat keterampilan prosesnya namun masih ada juga siswa yang kurang teliti, kurang tanggung jawab, dan menyesuaikan antara perkiraan awal dan hasil dalam proses pelaksanaan, sehingga keterampilan proses sains siswa dianggap masih kurang.

Salah satu alternatif yang dipandang mampu untuk meningkatkan keterampilan proses sains siswa tersebut dalam pembelajaran kimia serta memberikan kesempatan luas kepada siswa untuk terlibat langsung dalam memecahkan masalah dan maupun meningkatkan keterampilan proses sains siswa dalam' memecahkan masalah suatu permasalahan secara kreatif adalah model Creative Problem Solving.

Model Creative Problem Solving adalah suatu model pembelajaran yang melakukan pemusatan pada pengajaran dan keterampilan pemecahan masalah, yang diikuti dengan penguatan keterampilan. Ketika dihadapkan dengan masalah untuk memilih dan mengembangkan tanggapannya. Tidak hanya dengan menghafal tanpa dipikir, keterampilan memecahkan masalah (Pepkin,2004).
Menurut Sitiava (2013), keterampilan proses sains adalah kemampuan siswa untuk menerapkan metode ilmiah dalam memahami, mengembangkan dan menemukan ilmu pengetahuan. Keterampilan proses sains sangat penting bagi setiap siswa sebagai bekal untuk menggunakan metode ilmiah dalam mengembangkan sains serta diharapkan memperoleh pengetahuan baru atau mengembangkan pengetahuan yang telah dimiliki. Penelitian yang sama juga dilakukan dengan, Restika (2013) hasil penelitian menunjukkan bahwa model pembelajaran creative problem solving (CPS) dapat meningkatkan minat belajar siswa.

\section{METODE PENELITIAN}

Pendekatan dalam penelitian adalah menggunakan pendekatan campuran (mixed method). Mixed method merupakan metode yang memadukan pendekatan kualitatif dan kuantitatif dengan jenis model sequential exploratory (model urutanpenemuan) dimana data kuantitatif sebagai data primer atau data yang lebih dominan daripada data kualitatif.

Pendekatan kualitatif pada data ini mendeskripsikan secara naratif bagaimana guru/peneliti menerapkan model Creative Problem Solving (CPS) pada materi asam basa sedangkan pendekatan kuantitatif menilai hasil keterampilan proses sains siswa. Sampel dalam penelitian ini diambil dengan menggunakan teknik purposive sampling yaitu kelas XII PA 2 sebagai kelas eksperimen.

Instrumen yang digunakan dalam penelitian ini berupa lembar observasi dan tes essay (posttest). Lembar observasi digunakan untuk melihat keterlaksanaan model Creative Problem Solving (CPS) oleh guru dan siswa. Tes essay berupa posttest digunakan untuk melihat dan mendukung hasil keterampilan proses sains siswa. Teknik pengumpulan data yang digunakan ada 2 yakni data kualitatif diperoleh dari komentar observer pada lembar observasi, dan data kuantitatif diperoleh dari lembar observasi keterampilan proses sains. Teknik analisis data yang digunakan pada data kualitatif dianalisis menggunakan Miles and Huberman. Sedangkan data kuantitatif untuk melihat keterlaksanaan model dianalisis 
menggunakan korelasi product moment. Untuk melihat signifikansi pengaruh variabel $\mathrm{X}$ dan variabel Y maka dilakukan uji lanjut dengan uji t.

\section{HASIL DAN PEMBAHASAN}

Keterlaksanaan model Creative Problem Solving (CPS) dan keterampilan proses sains siswa pada materi asam basa di kelas XI IPA SMA Negeri 10 Kota Jambi mengalami peningkatan hasil persentasi keterlaksanaan oleh guru pada setiap pertemuan sebesar 62,50\% (Cukup Baik) untuk pertemuan pertama, 68,75\% (Cukup Baik) pada pertemuan kedua dan $78,75 \%$ (Baik) pada pertemuan ketiga dengan ratarata persentasi keterlaksanaan model sebesar 70,00\% (Baik).

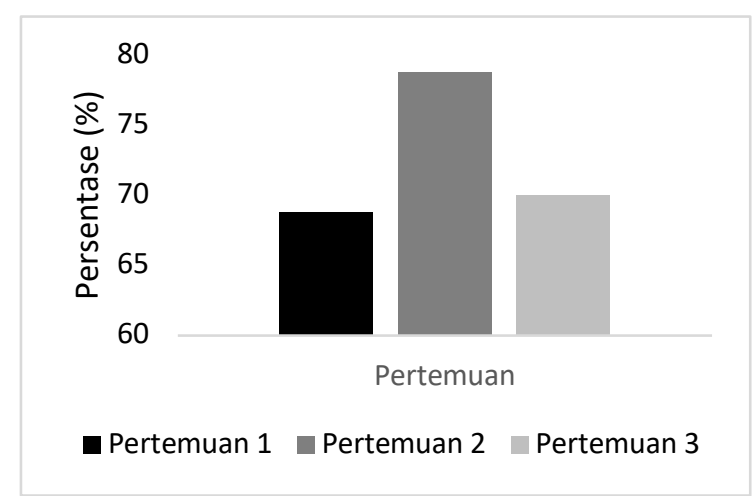

Gambar 1. Diagram persentase keterlaksanaan model pembelajaran CPS oleh guru

Keterlaksanaan model Creative Problem Solving dan keterampilan proses sains siswa pada materi asam basa di kelas XI IPA SMA Negeri 10 Kota Jambi mengalami peningkatan hasil persentasi keterlaksanaan oleh siswa pada setiap pertemuan sebesar 54,429\% (Cukup Baik) untuk pertemuan pertama, 72,19\% (Baik) pada pertemuan kedua dan $79,00 \%$ (Baik) pada pertemuan ketiga dengan rata-rata persentasi keterlaksanaan model sebesar $71,28 \%$ (Baik).

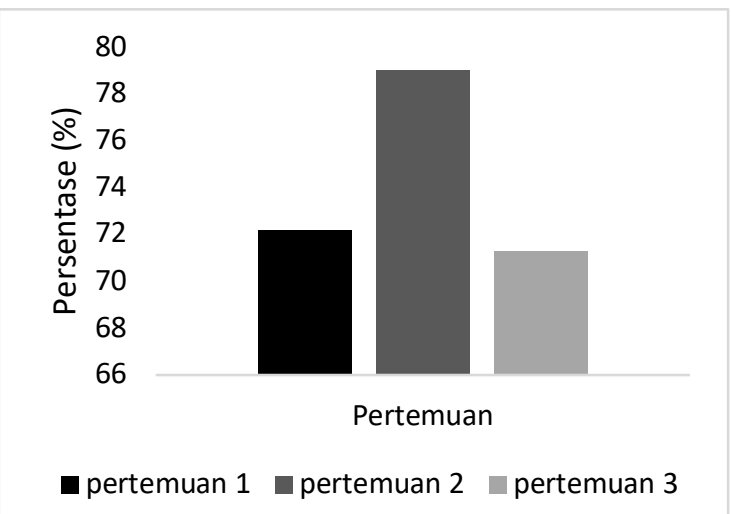

Gambar 2. Diagram persentase keterlaksanaan model pembelajaran CPS oleh siswa.

Keterlaksanaan model Creative Problem Solving dengan keterampilan proses sain siswa pada materi asam basa di kelas XI IPA SMA Negeri 10 Kota Jambi mengalami peningkatan hasil persentasi keterlaksanaan oleh siswa pada setiap pertemuan sebesar $65,15 \%$ untuk pertemuan pertama, $80,14 \%$ pada pertemuan kedua dan $80,72 \%$ pada pertemuan ketiga dengan rata-rata persentasi keterlaksanaan model sebesar 75,34\% (Baik).

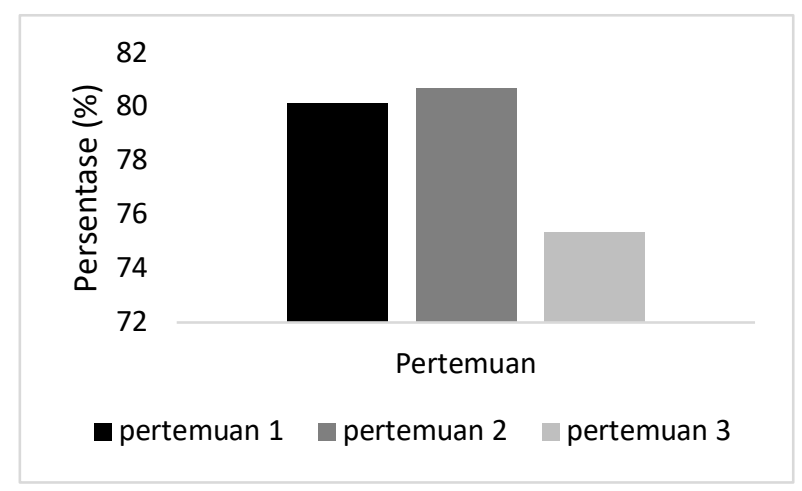

Gambar 3. Diagram persentase keterampilan proses sains siswa

Instrumen tes essay yang diberikan melalui posttest pada pertemuan ketiga dengan jumlah soal 10 soal essay dengan tingkat kognitif C1 sampai C4. Tes dilakukan untuk mendukung pengaruh keterampilan proses sains siswa.

Untuk melihat keterlaksanaan model Creative Problem Solving uji yang dilakukan yaitu dengan mencari korelasi product moment pearsonantara keterlaksanaan Creative Problem Solving (CPS) dengan keterammplan 
proses sains siswa. Dari perhitungan koefisien korelasi (r) diperoleh nilai (r) 0,4150. Berdasarkan tabel pedoman interpretasi koefisien korelasi nilai (r) 0,490 (sedang) pada (Sugiyono, 2016). Dengan demikian hubungan antara keterlaksanaan model pembelajaran Creative Problem Solving dengan keterampilan proses sains siswa pada penelitian ini memiliki tingkat hubungan sedang.

Selanjutnya dilakukan uji t,Hasil perhitungan pengaruh keterlaksanaan Creative Problem Solving dengan keterampilan proses sains siswa diperoleh nilai 0,169925. Nilai tersebut jika dibandingkan dengan $t_{\text {tabel }}=2,776$ maka diketahui $t_{\text {hitung }}>\mathrm{t}_{\text {tabel }}$ dengan $\mathrm{dk}=4$, berarti ada hubungan atau pengaruh positif antara keterlaksanaan model pembelajaran Creative Problem Solving (CPS) dengan keterammplan proses sains siswa pada materi asam basa di kelas XI SMA Negeri 10 Kota Jambi.Hasil perhitungan uji t untuk

\section{DAFTAR RUJUKAN}

Alawiyah, F., (2013). Dampak implementasi kurikulum 2013 terhadap guru. Info Singkat Kesejahteraan Sosial, 5(19),9-12.

Daryanto, (2014). Belajar dan mengajar. Bandung: Yrama Widya.

Depdiknas, (2013). Materi pelatihan guru implementasi kurikulum 2013 SMP/MTSilmu pengetahuan alam. Jakarta: Kemendikbud.

Depdiknas, (2003). Kurikulum 2004. Jakarta: Balitbang Depdiknas.

Dimyati \& Mudjiono, (2009). Belajar dan pembelajaran. Jakarta: PT. Rineka Cipta.

Hartantia, R.M., 2013. Penerapan model creative problem solving (CPS) untuk meningkatkan minat dan hasil belajar kimia pada materi pokok termokimia siswa kelas XII A SMA N Colomadu tahun pelajaran 2012/2013. Jurnal Pendidikan Kimia Surakarta melihat pengaruh keterlaksanaan model Creative Problem Solving dengan keterampilan proses sains siswa berarti ada hubungan atau pengaruh positif antara Creative Problem Solving dengan keterampilan proses sains siswa pada materi asam basa di kelas XI SMA Negeri 10 Kota Jambi.

\section{KESIMPULAN}

Berdasarkan hasil penelitian yang telah dilakukan, dapat diketahui bahwa rata-rata persentase keterlaksanaan model pembelajaran creative problem solving pada materi asam basa di kelas XI IPA SMAN 10 Kota Jambi sebesar 75,34\% dengan kategori baik sehingga dapat dikatakan terdapat korelasi keterlaksanaan model pembelajaran creative problem solving dengan keterampilan proses sains siswa dengan nilai $r_{x y}=0,4150$ dengan kategori hubungan yang sedang.

Pepkin, (2004). Creative problem solving in math. Diakses pada tanggal 15 Desember 2014 dari http://www.uh.edu/hti/cu/ 2004/v02/04.htm.

Rizema, P.S., (2013). Kreasi mainan anak nusantara. Yogyakarta: Nayra Pustaka.

Rustaman, N., 2003. Pokok-pokok pengajaran biologi dan kurikulum. Jakarta: Pusbub Depdikbud.
Rustaman, (2011). Model-model pembelajaran: Mengembangkan profesionalisme. Jakarta: PT. Rajagrafindo Persada.

Sugiyono, (2014). Metode penelitian Pendidikan. Bandung:Alfabeta.

Sugiyono, (2016). Metode penelitian pendidikan. Bandung:Alfabeta. 